\section{SYNLETT Spotlight 163}

This feature focuses on a reagent chosen by a postgraduate, highlighting the uses and preparation of the reagent in current research

\section{Bromodimethylsulfonium Bromide (BDMS): A Versatile Reagent in Organic Synthesis}

\author{
Compiled by Md Lokman Hakim Choudhury
}

Md Lokman Hakim Choudhury was born at Rangia, Assam in India. He received his BSc from Gauhati University. Later on he joined the Indian Institute of Technology Guwahati where he completed his MSc in Chemistry in 2003. Subsequently, he joined Dr. Khan's research group in the Department of Chemistry, at IIT Guwahati to pursue his doctoral studies. His current research interest is to develop new synthetic methodologies using both homogeneous and heterogeneous catalysts. He is interested in some of their applications towards synthesis of bioactive natural products and some aspects of domino reactions.

Department of Chemistry, Indian Institute of Technology

Guwahati, Guwahati 781 039, India

E-mail: mlhc@iitg.ernet.in; E-mail: lokman_iitg@yahoo.com

Dedicated to my mentor Prof. Abu T. Khan

\title{
Introduction
}

Bromodimethylsulfonium bromide (BDMS) (Figure 1) is a light orange solid compound, which has been used extensively in various organic transformations. It can easily be prepared from molecular bromine and dimethylsulfide. ${ }^{1}$ It can also be generated in situ from the reaction of dimethylsulfoxide and aqueous $\mathrm{HBr}^{2}$ BDMS can be considered a convenient storage for the bromonium ion, just as hypobromite, $\mathrm{N}$-bromosuccinimide or bromoazide. After Meerwein's discovery of bromodimethylsulfonium

\begin{abstract}
s
(A) Preparation of alkyl bromides from corresponding alcohols: Furukawa et. al first demonstrated the application of this reagent for the conversion of alcohols to bromides in high yield. The reaction proceeds via an inversion, i.e. an optically active alcohol gives the corresponding bromide with inversion of configuration. ${ }^{11}$

(B) Conversion of epoxides and enamines to a-haloketones: Epoxides upon treatment with halodimethylsulfonium halides (chloride/bromide) in the presence of triethyl amine give $\alpha$-halo ketones in high yields. The reaction proceeds well with alkene oxides and cycloalkene oxides of small ring sizes. Epoxides with medium and large ring sizes undergo transannular rearrangements, giving mixtures of products. Similarly, enamines react with BDMS to give $\alpha$-bromoketones. ${ }^{12}$
\end{abstract}

bromide in $1965,{ }^{3}$ it has gained considerable interest in current organic chemistry due to its easy handling and low cost, its easy access and varied application both as catalyst, ${ }^{4-10}$ as well as an effective reagent.<smiles>C[SH](C)Br</smiles>

Figure 1 Bromodimethylsulfonium bromide (BDMS)

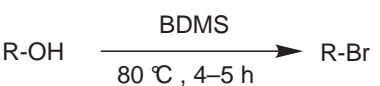<smiles>[R]C1CO1</smiles><smiles>[R][C@H](C)S([Y])(C)C</smiles><smiles>[R]C(=O)C([R])([R])C</smiles>
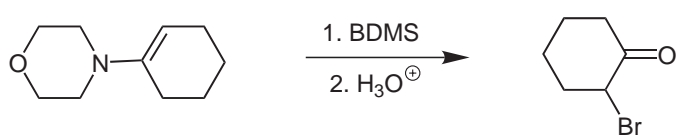

SYNLETT 2006, No. 10, pp 1619-1620

Advanced online publication: 12.06.2006

DOI: 10.1055/s-2006-941579; Art ID: V16706ST

(c) Georg Thieme Verlag Stuttgart · New York 
(C) Electrophilic addition to olefins:

Chow et. al showed that bromdimethylsulfonium bromide reacts with various alkenes and provides corresponding addition product sulfonium bromides in good yields. The resultant sulfonium bromide on treatment with aqueous potassium carbonate gives dehydrobrominated products. ${ }^{13}$

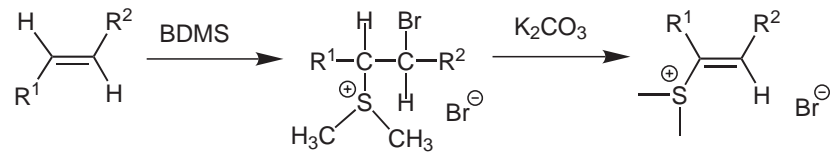

(D) Efficient synthesis of a-bromo enones from enones:

Bromodimethylsulfonium bromide reacts with conjugated enones at $\leq 0^{\circ}$ and give $\alpha$-bromo- $\beta$-sulfonium carbonyl compounds, which on subsequent treatment with aqueous $\mathrm{K}_{2} \mathrm{CO}_{3}$ give $\alpha$-bromo enones in excellent yields. ${ }^{14}$

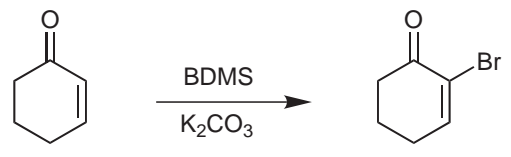

(E) Regioselective para-halogenation of activated arenes:

Bromodimethylsulfonium bromide as well as its chloro analogue is an efficient regioselective halogenating agent for activated aromatics such as phenols, anisole, diphenyl ether and $\mathrm{N}$-alkyl anilines. ${ }^{15}$ The observed high para selectivity is a consequence of the transfer of halogens going through a 'late' arenium ion like transition state and of the bulky nature of the halogenating agents. For para-substituted aromatics it gives no halogenations.

(F) Deprotection of thioacetals and protection of carbonyl compounds as acetals, oxathioacetals and thioacetals:

Bromodimethylsulfonium bromide (a soft electrophilic brominating agent) in stoichiometric amount combines with the soft sulfur atoms of thioacetals and gives the bissulfonium ion (A), which subsequently can be hydrolyzed to the corresponding ketones. ${ }^{1}$ On<smiles>Oc1ccc(Br)cc1</smiles>

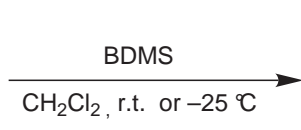

$80-94 \%$<smiles>Oc1ccc(Br)cc1</smiles>
the other hand, a catalytic amount of BDMS is effective for thioacetalization, acetalization, transthioacetalization, ${ }^{9}$ as well as oxathioacetalization ${ }^{6}$ of carbonyl compounds.

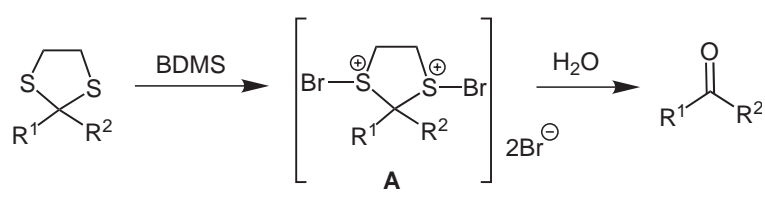

(G) Electrophilic aromatic bromination by in situ generated BDMS: Majetich et al. showed that BDMS, generated in situ by treating DMSO with aqueous $\mathrm{HBr}$, is a milder and more selective reagent for electrophilic aromatic bromination than elemental bromine. ${ }^{2}$ Indole alkaloids can also be brominated using the same reagent. ${ }^{16}$

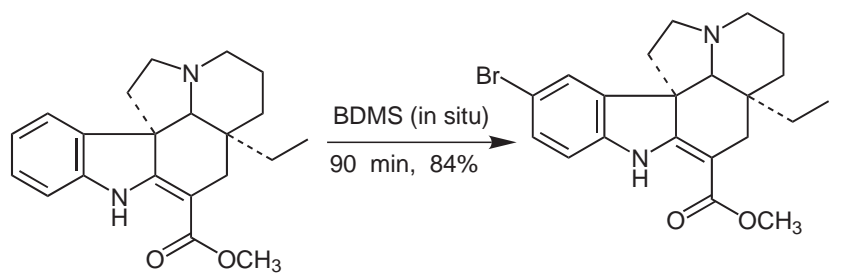

\section{References}

(1) Olah, G. A.; Vankar, Y. D.; Arvanaghi, M.; Surya Prakash, G. K. Synthesis 1979, 720.

(2) Majetich, G.; Hicks, R.; Reister, S. J. Org. Chem 1997, 62, 4321.

(3) Meerwein, H.; Zenner, K. F.; Gipp, R. Justus Liebigs Ann. Chem. 1965, 67, 688.

(4) Kudrimoti, S.; Bommena, V. R. Tetrahedron Lett. 2005, 46, 1209.

(5) Khan, A. T.; Islam, S.; Majee, A.; Chattopadhyay, T.; Ghosh, S. J. Mol. Catal. A: Chem. 2005, 239, 158.

(6) Khan, A. T.; Sahu, P. R.; Majee, A. J. Mol. Catal. A: Chem. 2005, 226, 207.

(7) Das, B.; Ramu, R.; Ravikanth, B.; Reddy, V. S. J. Mol. Catal. A: Chem. 2005, 246, 76.

(8) Khan, A. T.; Mondal, E.; Borah, B. M.; Ghosh, S. Eur. J. Org. Chem. 2003, 4113.

(9) Khan, A. T.; Mondal, E.; Ghosh, S.; Islam, S. Eur. J. Org. Chem. 2004, 2002.

(10) Rani, S.; Babu, J. L.; Vankar, Y. D. Synth. Commun. 2003, 33, 4043.

(11) Furukawa, N.; Inoue, T.; Aida, T.; Oae, S. Chem. Commun. 1973, 212.

(12) Olah, G. A.; Vankar, Y. D.; Arvanaghi, M. Tetrahedron Lett. 1979, 38, 3653.

(13) Chow, Y. L.; Bakker, B. H. Synthesis 1982, 648.

(14) Chow, Y. L.; Bakker, B. H. Can. J. Chem. 1982, 60, 2268.

(15) Olah, G. A.; Ohannesian, L.; Arvanghi, M. Synthesis 1986, 68.

(16) Megyeri, G.; Keve, T. Synth. Commun. 1989, 19, 34. 